\title{
Efficacious Scrutinizing of COVID-19 Impact on Banking Using Credit Risk Metrics
}

\author{
Samej Wakode \\ Department of Management Studies, Jamnalal Bajaj Institute of Management Studies, Mumbai, India \\ Email address: \\ samej20wakode@gmail.com

\section{To cite this article:} \\ Samej Wakode. Efficacious Scrutinizing of COVID-19 Impact on Banking Using Credit Risk Metrics. International Journal of Finance and \\ Banking Research. Vol. 6, No. 3, 2020, pp. 51-56. doi: 10.11648/j.ijfbr.20200603.13
}

Received: May 15, 2020; Accepted: May 28, 2020; Published: June 4, 2020

\begin{abstract}
COVID-19 (coronavirus disease 2019) pandemic has affected the length and breadth of various industries and banking is one of the most distressed sectors. The main objective of the paper was to manifest the influence of COVID-19 on the credit exposure of a bank. Conventional risk management of a bank is having its business intelligence dashboard to monitor credit exposure and make vital decisions based on it. But because of uncertainty like an epidemic, COVID-19, those visualizations/information fail to convey the impact of an epidemic on the business of a bank and create a gap, which in turn hurts the institution being not able to make accurate and strategic decisions. To bridge that gap, this study uses a statistical technique - Multivariate analysis of variance to choose and find out risk metrics for a bank which has a significant impact because of COVID-19 and developed a COVID-19 risk indicator parameter, which is the integrated measure of both COVID19 data and credit risk metrics. The analysis uses a business intelligence tool, Tableau, to visualize geographically impact for a bank as per selected risk metrics and also displays industry-wise impact by integrated results of COVID-19 data, which extracts summarize version of most/least impacted counties and most/least impacted industries concerning bank exposure because of an epidemic. The study concluded that having this methodology and visualization of information available to risk management department or senior management of a bank, this will help them to make decisions like industry-wise relaxation on the credit products, before an asset becomes sub-standard take proactive measures such as debt restructuring, by looking at most impacted industries and banks credit exposure, appraise the provisioning factor and many more critical decisions.
\end{abstract}

Keywords: COVID-19, Credit Risk Metrics, Risk Management of Bank, Visualization

\section{Introduction}

The epidemic, COVID-19, has forced the financial institutions and its risk functions, including the banking sector, to form crisis plans and take required measures to mitigate the impact on its health [1]. The Basel Committee on Banking Supervision has also agreed that this pandemic will have a direct impact on credit losses of a bank [2].

In such a scenario, it is important for the risk management of a bank to take critical and strategic decisions to confront the situation effectively $[3,4]$. Conventionally, it's very rare for a bank to have established proactive measures to tackle an impact caused by an epidemic, such as how an epidemic is affecting the business of a bank, built-in the relation between the bank's exposure geography wise versus impact caused by an epidemic and how various industries are reacting to it $[5,6]$. To resolve these concerns, banks need to develop their customized risk indicator about COVID-19 and create a dashboard showcasing meaningful information geography-wise and industry-wise.

To achieve that, the study focuses on two vital parts: (1) Deciding risk key metrics using statistical methods, and (2) Based on the above metrics, develop a COVID-19 risk parameter and come up with a visualization of integration between COVID-19 and risk metric data as per geography and industry classification.

\section{Key Credit Risk Metrics}

It is very critical to choose appropriate risk metrics, which is the core of the analysis, to showcase the impact of an epidemic [7]. Each bank has its core competencies and based on that they can select respective risk metrics, which is suitable to them. To generalize and illustrate the common impact, this study uses three broad risk credit metrics (based 
on the availability of data) for an analysis of Author Name et al.: Paper title COVID-19 impact which most of the banks can relate. They are, namely: Total exposure/Binding exposure, past-due loans $(90+$ days $)$, and loss given default/Total loss outstanding Amount.

Details of risk metrics

\subsection{Total Exposure/Binding Exposure}

It is the sum of the lender's unused commitment and the outstanding principal/interest balance of the loans.

This is the total amount of risk bank is exposed with and that's why it's important to have a gauge of it [8]. But for its effectiveness in an epidemic scenario, there is a need to represent this metric by integrating with geography/ counties data having an impact of COVID-19.

This will help to identify the total risk exposure that a bank is having as per geography/counties, comprising of COVID19 impact. With the use of the "North American Industry Classification System (NAICS) code", industry-wise exposure is also possible to showcase which will help to identify industry-wise exposure of a bank.

\subsection{Past Due Loans (90+ Days)}

It is the credit loans of a bank which are having default payments of $90+$ days [9].

COVID-19 hit most of the industries hurting it, like a sudden rise in unemployment, hitting the top line of business. This may result in the irregularity of the payment by them. It's an impact on the business is not long term, business needs to look for those loans which are recently turning from standard to sub-standard [10].

\subsection{Loss Given Default/Total Loss Outstanding Amount}

It is the amount of money a bank loses when a borrower defaults on a loan and it is calculated after reviewing all outstanding loans using cumulative losses and exposure [11].

This helps the bank to project out their expected losses because of the defaulting of loans by borrowers. To take proactive steps like debt restructuring and provisioning [12], it is important to take note of this parameter.

\section{Research Methodology}

\subsection{Data Collection}

This study considers the data of a bank on selected credit risk parameters. The data used for analysis are obtained from secondary sources like reports published by banks, data from the financial services authority, government sources, and COVID-
19 related data from the John Hopkins University website. The sample is used for the development of coefficients between the risk metrics and COVID-19 data. Also, the North American Industry Classification System (NAICS) code is used for industry-wise COVID-19 impacts concerning geography and risk metrics, which is publicly available. For analysis. the classification of data is done in two-time frames: Before COVID-19 data and after COVID-19 data.

\subsection{Model Description}

This study uses the Multivariate analysis of variance (MANOVA) [13], which is simply an ANOVA with several dependent variables. That is to say, ANOVA tests for the difference in means between two or more groups, while MANOVA tests for the difference in two or more vectors of means [13]. Variables used in the model:

Independent variable/factor with 2 levels - Before COVID19 data and After COVID-19 data,

Dependent variables/factors - Total Exposure, Past-due loans (90+days), and Loss given default

To decide the appropriateness of selected risk metrics, it is necessary to find out whether the impact of COVID-19 on the risk metrics is significant or not. To analyze the same, model's null hypothesis and alternate hypothesis are, respectively:

H0: COVID-19 data did not have any significant effect on the Risk metrics of a bank, and

H1: COVID-19 data had a significant effect on the values of risk metrics

The significance level, i.e. alpha or $\alpha$, is considered as 0.05 , which is a probability of rejecting the null hypothesis when it is true.

Table 1. One-way MANOVA.

\begin{tabular}{llll}
\hline & Stat & F-Value & P-Value \\
\hline Pillai Trace & 0.9250505 & 16.456422 & 0.0102657 \\
Wilk's Lambda & 0.0749495 & 16.456422 & 0.0102657 \\
Hotelling Trace & 12.342317 & 16.456422 & 0.0102657 \\
Roy's Lg Root & 12.342317 & & \\
\hline
\end{tabular}

The table shows that $\mathrm{P}$-value is less than the alpha, which is $5 \%$ or 0.05 , so we can reject the null hypothesis. Or in simple terms, it means COVID-19 data did have a significant effect on the risk metrics of a bank.

But we still cannot tell which risk metric was affected by the COVID-19 and which wasn't. This is one of the limitations of MANOVA; even if it tells us whether the effect of a factor on a population was significant or not, it does not tell us which dependent variable was affected by the factor introduced [13].

We can get a clearer picture of this with the help of multiple ANOVA.

\subsection{Multiple ANOVA}

Table 2. ANOVA: Single Factor - Total Exposure.

\begin{tabular}{llllll}
\hline Sources & SS & df & MS & F & P value \\
\hline Between Groups & $4 \mathrm{E}+09$ & 1 & $4.4 \mathrm{E}+09$ & 15.2 & 0.00799 \\
Within Groups & $2 \mathrm{E}+09$ & 6 & $2.9 \mathrm{E}+08$ & & \\
Total & $6 \mathrm{E}+09$ & 7 & $8.8 \mathrm{E}+08$ & \\
\hline
\end{tabular}


The table shows that F-value is greater than the F-critical value and P-value is less than alpha value. As P-value lies in a significant region, this means that COVID-19 data had a significant effect on the values of total exposure.

Table 3. ANOVA: Single Factor - Past due loans (90+ days).

\begin{tabular}{lllllll}
\hline Sources & SS & df & MS & F & P value & F crit \\
\hline Between Groups & 234.6 & 1 & 234.578 & 12 & 0.01339 & 10.81 \\
Within Groups & 117.3 & 6 & 19.5445 & & & \\
Total & 351.8 & 7 & 50.2635 & & & \\
\hline
\end{tabular}

The table shows that F-value is greater than the F-critical value and P-value is less than the alpha value. So, as like total exposure, this signifies that COVID-19 data had a significant effect on the values of Past-due loans (90+ days).

Table 4. ANOVA: Single Factor - Loss given default.

\begin{tabular}{llllll}
\hline Sources & SS & df & MS & F & P value \\
\hline Between Groups & 7.861 & 1 & 7.86061 & 4.894 & 0.06894 \\
Within Groups & 9.638 & 6 & 1.60631 & & \\
Total & 17.5 & 7 & 2.49978 & & \\
\hline
\end{tabular}

As the table shows, the F-value is less than the F-critical value and also $\mathrm{P}$-value is more than alpha value. So, $\mathrm{P}$-value does not lie in the significant region, this means that COVID19 data did not have any significant effect on the values of loss given default.

\section{Business Intelligence Views}

The crux of the study lies in the views created below, which are being developed using the BI tool, Tableau. But, this can be extended to other BI tools like Qlikview, Power BI. The only purpose to showcase the view is to have a meticulous thought process to convert the data into meaningful information with which management can take critical and important decisions.

\subsection{Geography Integrated View}

To showcase how one particular county or geography is being affected because of COVID-19 and at what intensity that impact is hitting the business of a bank, it is necessary to represent this integration in a quantifying manner.

The combined effect of COVID-19 active cases and death count per county is calculated by using parameter COVID-19 Exposure density (CED). CED is the weighted average of the number of COVID-19 active cases and deaths per thousand populations for a county or as per geography. Weight (X) needs to be given to each variable (active cases and death count) as per business discretion.

$$
\mathrm{CED}=[(\mathrm{A} * \mathrm{X}+\mathrm{D} *(1-\mathrm{X})] / 2
$$

$A=$ Active cases per thousand populations for a county $\mathrm{D}=$ Death count per thousand populations for a county $\mathrm{X}=$ Weight given to a variable

Based on the availability of data, this equation can be enhanced by adding more factors such as the number of critical cases and discharge cases.

CED is calculated for each county and then it is mapped with the selected risk metrics to get the view as shown in Figure 1. In Figure 1, the intensity of the color of the box denotes the COVID-19 impact to that county (Red - Most affected and Green - Least impacted) and the size of the box denotes the quantitative value of the risk metrics.
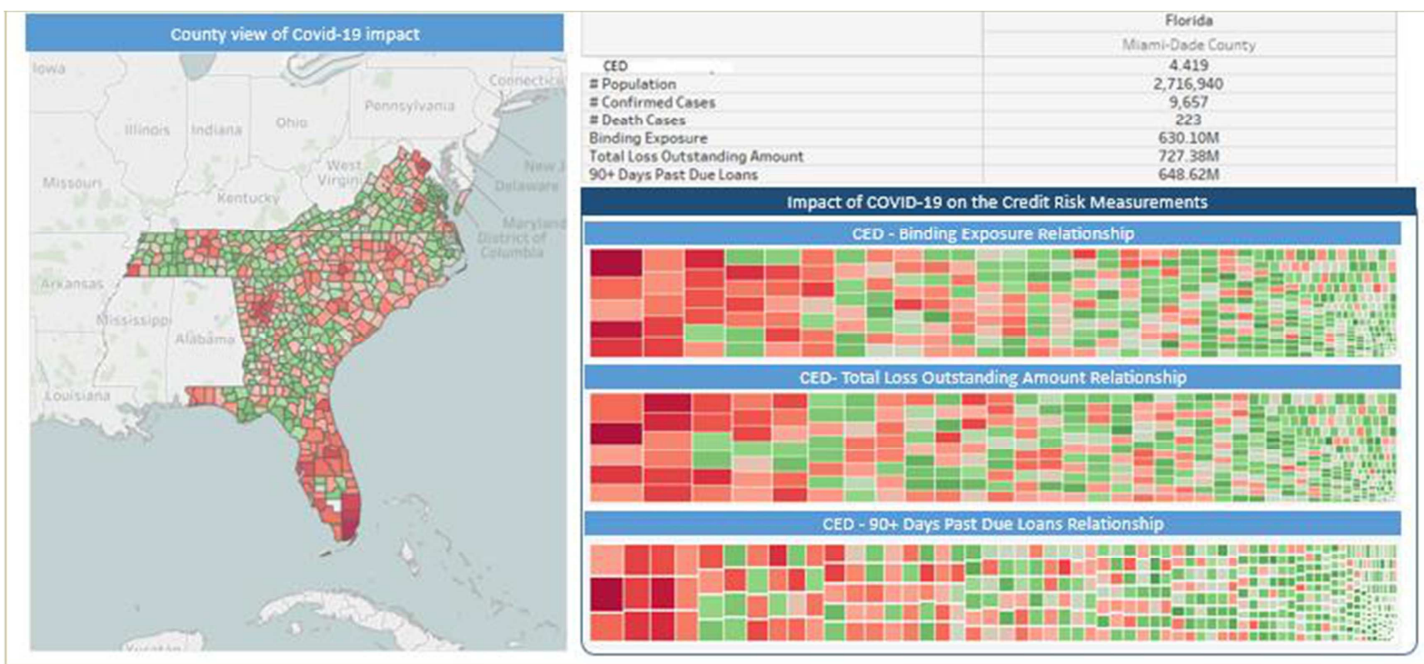

Figure 1. Geography Integrated View. 
The visualization in the above figure is depicting the impact of COVID-19 for each county, where the bank is having business with. To demonstrate this, when the user hovered around the Florida region on the map, it will display additional information about that region and will intensify the.

\subsection{Industry Integrated View}

It is important to gauge how industries are reacting to the COVID-19 impact $[6,14]$. To achieve that, there is a need to find integration between COVID-19 data and risk metrics of a bank. COVID-19 Industry Risk Parameter (CIRP) is an index which tells the intensity of convergence of COVID-19 data and risk measures, which is defined as:

$$
\mathrm{CIRP}=[(\ln (\mathrm{x}+\mathrm{M}) * \mathrm{~S}) * \mathrm{~W} 1+(\ln (\mathrm{y}+\mathrm{N}) * \mathrm{~S}) * \mathrm{~W} 2+(\ln
$$

$\mathrm{x}=$ Percentage change of Total exposure from previous month $y=$ Percentage change of Past due loans from previous month $\mathrm{z}=$ Percentage change of Loss given default from previous month respective boxes in the view. This will help to interpret the COVID-19 impact on the business as per selected risk metrics and also with respect to the geography. This view will assist the management to take key decisions based on geography.

$$
\begin{aligned}
& \mathrm{M}=(-1) *(\text { Largest negative number of } \mathrm{x})+0.01 \\
& \mathrm{~N}=(-1) *(\text { Largest negative number of } \mathrm{y})+0.01 \\
& \mathrm{O}=(-1) *(\text { Largest negative number of } \mathrm{z})+0.01
\end{aligned}
$$

$$
\mathrm{W} 1+\mathrm{W} 2+\mathrm{W} 3=1
$$

Weight is given to each parameter

$\mathrm{S}=$ Quantitative number to represent the effect of active cases and deaths because of COVID-19.

Based on the availability of data, equation (2) can be enhanced by adding macro-economic factors like unemployment and consumer price index [15]. The resulting number from (2) is converted into a standard range to display category wise impact with the help of NAICS code.

The view in Figure 2 is depicting the industry-wise classification, using CIRP, for the geography. Also, how the bank is exposed because of COVID-19 to a particular industry is displayed by considering selected risk metrics. This visualization will help in monitoring how industries are performing during an epidemic timeframe and which geography is more critical to the bank as regards to the industry can also be examined, which is the need of a situation.

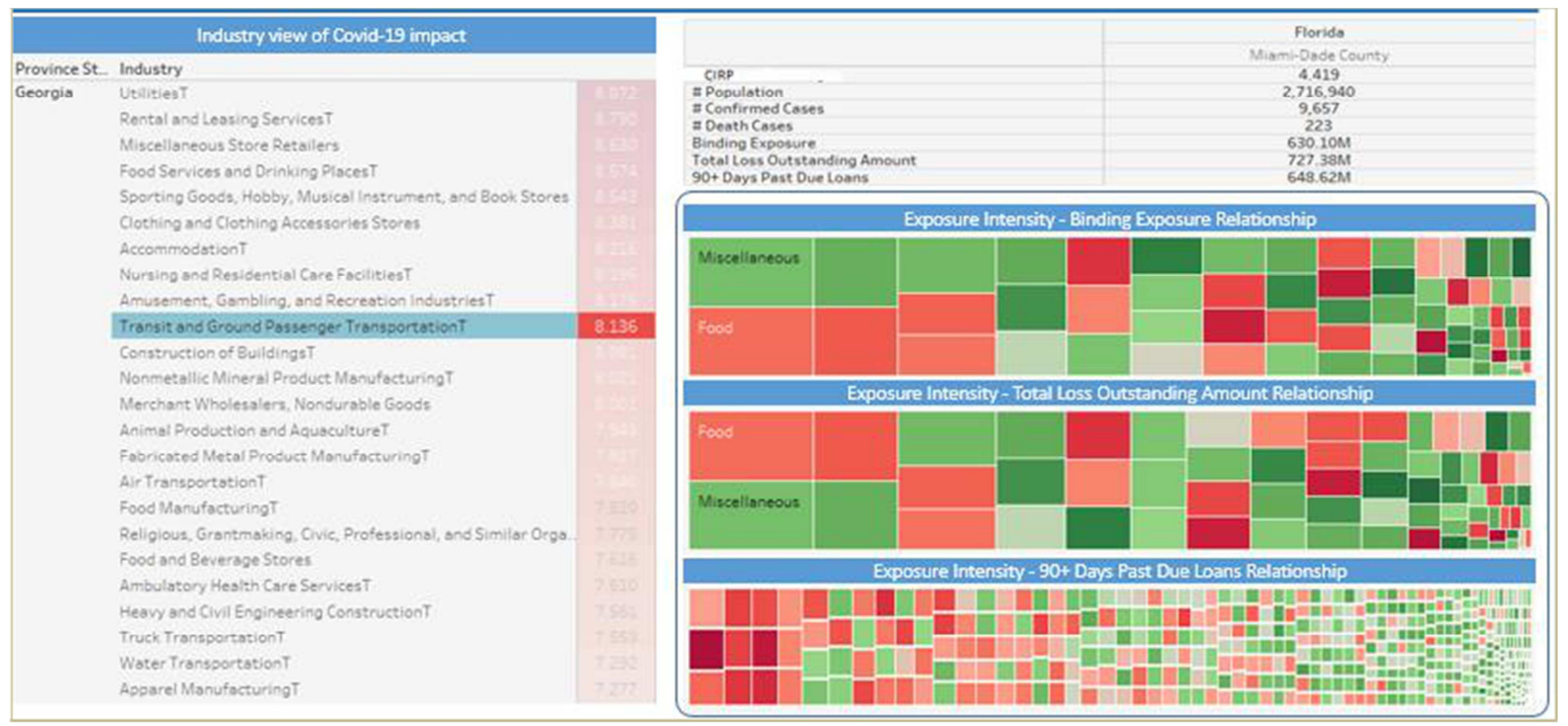

Figure 2. Industry Integrated View.

\subsection{Summarized View of COVID-19 Impact on Geography and Industry}

This view is the resultant of all explanations provided in the study. It gives the summary version of the impact of COVID-19 on the business. It is vital for the management of a bank to extract the most impacted and least impacted industries to take strategic decisions based on that [16]. The same is displayed in Figure 3.

Also, for the risk monitoring, there is a need to know which county/geography is being majorly affected or scarcely affected [16], which is mentioned in the below view. This will assist in making critical decisions and steps based on geography. 


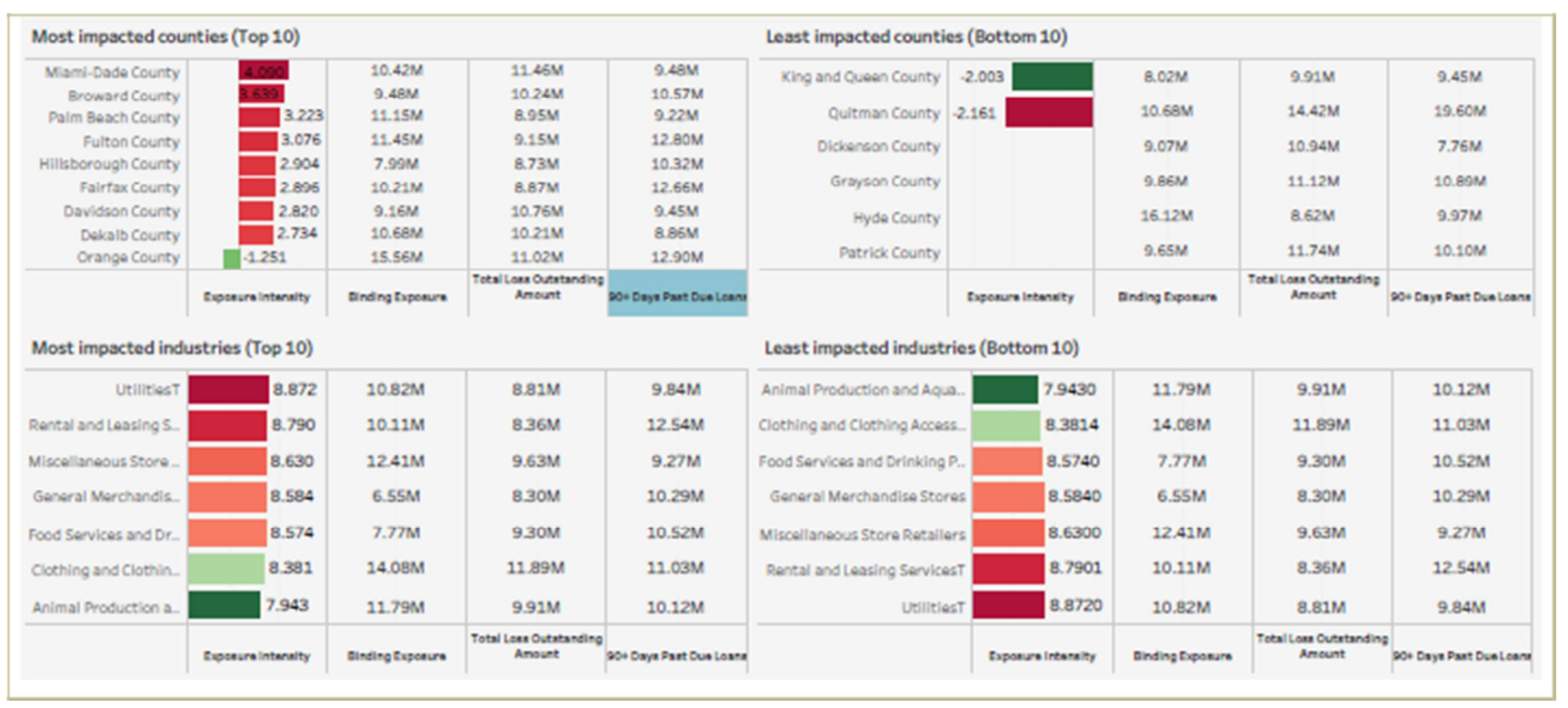

Figure 3. Summarized View.

\section{Conclusions}

The analysis in the study helps to extract the insight of risk key measures of a bank affected by an epidemic. To support the significance of the risk metric chosen, the statistical techniques used in the study provide evidence to consider the same as a critical one. The visual representation, which is the core of a study, uses two key derived COVID-19 risk parameters, namely: CED (COVID19 exposure density) and CIRP (COVID-19 Industry Risk Parameter). These parameters give strength to the visualization to display convergence of COVID-19 impact and risk metrics.

The views explained in the study can lead the management of a bank in taking key proactive decisions like industry-wise relaxation on the credit products, before an asset becomes sub-standard take proactive measures such as debt restructuring, Target promoting of products based on geography view to have more conversion rate i.e. converting potential clients into active clients, focusing on commercial clients who are in the green zone for attracting new business, by looking at most impacted industries and banks credit exposure appraise the provisioning factor and segmentation of clients which are in high-risk sectors and those likely to be affected. The given list of applications is just exploratory but not exhaustive and it depends on how one wants to extract insights from the visualization.

\section{References}

[1] Oliver Wyman Report (2020, March 5) COVID-19: How Should Risk Functions Respond? Retrieved from https://www.oliverwyman.com/our-expertise/insights/2020/ma r/covid19-risk.html.

[2] Basel Committee on Banking Supervision Report (2020, April) Measures to reflect the impact of Covid-19. Retrieved from https://www.bis.org/bcbs/publ/d498.pdf.

[3] Konovalova N., Kristovska I., Kudinska M. (2016, June). Credit risk management in commercial banks. Polish Journal of Management Studies, 13 (2), 90-100.

[4] Njanike, K (2009). The Impact of Effective Credit Risk Management on Bank Survival. Annals of the University of Petrosani, Economics, 9 (2), 173-184.

[5] Thomas Zink, Martin stiller (2020, March 26). COVID-19 and its Impact on the Banking Industry. Retrieved from https://blogidcuk.com/covid-19-impact-banking-industry/.

[6] Shaun Crawford (2020, April 8). How can your industry respond at the speed of COVID-19's impact? Retrieved from https://www.ey.com/en ae/covid-19/how-can-your-industryrespond-at-the-speed-of-covid-19s-impact.

[7] Jim Marous (2020, March 12). How Will the Coronavirus Impact the Banking Ecosystem? Retrieved from https://thefinancialbrand.com/93679/digital-banking-fintech-fi nance-investment-coronavirus-impact-trends/.

[8] Juliane Begenau, Monika Piazzesi, Martin Schneider (2015, June). Banks' Risk Exposures. Retrieved from https://web.stanford.edu/ piazzesi/banks.pdf.

[9] Basel Committee on Banking Supervision Report (n.d). Prudential treatment of problem assets - definitions of nonperforming exposures and forbearance. Retrieved from https://www.bis.org/bcbs/publ/d403.pdf.

[10] Thorsten Beck (2020, March 2). Finance in the times of coronavirus. Economics in the Time of COVID-19 (73-76).

[11] Alicia Tuovila (2019, September 6). Loss Given Default. Retrieved from https://www.investopedia.com/terms/1/lossgivendefault.asp.

[12] Benjamin M. Friedman (2000, May). Debt restructuring. Retrieved from https://www.nber.org/papers/w7722.pdf.

[13] James W. Grice, Michiko Iwasaki (2007). A Truly multivariate approach to MANOVA. Applied Multivariate Research, 12 (3), 199-226. 
[14] Nick Masters (2020. Feb 13). Industry Impacts of the Coronavirus. Retrieved fromhttps://www.ibisworld.com/industry-insider/coronavirusinsig hts/industry-impacts-of-the-coronavirus/.

[15] Chris Miller (2020, March 30). The Effect of COVID-19 on the U.S. Economy. Retrieved from https://www.fpri.org/article/2020/03/the-effect-of-covid-19on-the-u-s-economy/.
[16] McKinsey \& Co. Report (2020, March 17). Leadership in the time of coronavirus: COVID-19 response and implications for banks. Retrieved from https://www.mckinsey.com/industries/financial-services/ourinsights/leadership-in-the-time-of-coronavirus-covid-19response-and-implications-for-banks. 